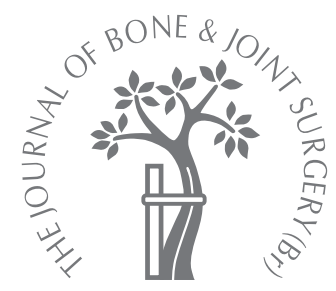

\title{
The effect of shortening and varus collapse of the femoral neck on function after fixation of intracapsular fracture of the hip
}

\author{
A MULTI-CENTRE COHORT STUDY
}
M. Zlowodzki,
O. Brink,
J. Switzer,
S. Wingerter,
J. Woodall,
B. A. Petrisor,
P. J. Kregor,
D. R. Bruinsma,
M. Bhandari

From McMaster

University, Hamilton, Canada

M. Zlowodzki, MD,

Orthopaedic Surgery Resident

J. Switzer, MD, Orthopaedic

Surgeon, Assistant Professor

University of Minnesota, 2450

Riverside Avenue S, R200,

Minneapolis, Minnesota 55454,

USA.

- O. Brink, MD, PhD, MPA,

Orthopaedic Surgeon, Assistant

Professor

Aarhus University,

Nørrebrogade 44, 8000 Aarhus

C, Denmark.

I. Wingerter, MD,

Orthopaedic Surgery Residen

J. Woodall Jr, MD,

Orthopaedic Surgery Resident

University of Mississippi $2500 \mathrm{~N}$.

State Street, Jackson,

Mississippi 39216, USA

B. A. Petrisor, MD, MSc

Orthopaedic Surgeon, Assistant

Professor

D. R. Bruinsma, MD, Resident

M. Bhandari, MD, MSc,

Associate Professor MSc,

Assor Canada

Chai

Hamilton General Hospital, 7

North, Suite 727, 237 Barton

Street, Hamilton, Ontario L8L

2X2, Canada.

P. J. Kregor, MD, Orthopaedic Surgeon, Associate Professor Division of Orthopaedic Trauma Division of Orthopaedic Trauma Vanderbilt University Medical Center, 131 Medical Center South, 2100 Pierce Avenue, Nashville, Tennessee 37232 3450, USA.

Correspondence should be sent to $\operatorname{Dr}$ M. Zlowodzki; e-mail: zlowo001@umn.edu

(C)2008 British Editorial Society of Bone and Joint Surgery doi:10.1302/0301-620X.90B11. $20582 \$ 2.00$

$J$ Bone Joint Surg $[\mathrm{Br}]$ 2008:90-B:1487-94.

Received 7 December 2007:

Accepted after revision 9 May

2008

\begin{abstract}
We have studied the effect of shortening of the femoral neck and varus collapse on the functional capacity and quality of life of patients who had undergone fixation of an isolated intracapsular fracture of the hip with cancellous screws. After screening 660 patients at four university medical centres, 70 patients with a mean age of 71 years $(20$ to 90$)$ met the inclusion criteria. Overall, $66 \%$ (46 of 70 ) of the fractures healed with $>5 \mathrm{~mm}$ of shortening and $39 \%$ (27 of 70 ) with $>5^{\circ}$ of varus. Patients with severe shortening of the femoral neck had significantly lower short form-36 questionnaire (SF-36) physical functioning scores (no/ mild $(<5 \mathrm{~mm}$ ) vs severe shortening $(>10 \mathrm{~mm}) ; 74$ vs 42 points, $p<0.001)$. A similar effect was noted with moderate shortening, suggesting a gradient effect (no/mild $<5 \mathrm{~mm}$ ) vs moderate shortening ( 5 to $10 \mathrm{~mm}$ ); 74 vs 53 points, $p=0.011$ ). Varus collapse correlated moderately with the occurrence of shortening $(r=0.66, p<0.001)$. Shortening also resulted in a significantly lower EuroOol questionnaire (EQ5D) index scores $(p=0.05)$. In a regression analysis shortening of the femoral neck was the only significant variable predictive of a low SF-36 physical functioning score $(p<0.001)$.
\end{abstract}

Each year 280000 North Americans sustain a fracture of the hip. ${ }^{1,2}$ This figure is likely to exceed 500000 in the United States and 4.5 million worldwide over the next 30 to 50 years. ${ }^{2-4}$ Approximately half of these will be intracapsular fractures of the neck of the femur. $^{4}$

The most commonly used devices for fixation of intracapsular fractures of the hip are multiple parallel screws or a sliding hip screw. ${ }^{5-12}$ They both let the fracture fragments slide along the implant, compressing the fracture when subjected to an axial load during weight-bearing. The rationale behind this concept is the promotion of fracture healing by compression of the fragments. However, these methods of fixation may lead to shortening of the femoral neck, thereby changing the moment arm for the abductor muscles of the hip and the overall mechanics. Shortening of the abductor moment arm has been described as having a negative effect on abductor function in patients who have undergone a total hip replacement. ${ }^{13-16}$ However, this has attracted little attention in the literature of orthopaedic trauma.

We recently surveyed 160 orthopaedic surgeons, $82 \%$ of whom believe that shortening of the femoral neck is common after internal fixation of intracapsular fractures of the hip with multiple parallel screws. In addition, $70 \%$ believe that this limits the patient's mobility and gait. ${ }^{17}$ In a limited retrospective clinical pilot study of 56 patients treated with three cancellous screws we found that shortening occurred in $30 \%$ of displaced and undisplaced fractures. ${ }^{18}$ Despite having found significantly higher physical functioning short form questionnaire (SF-36) subscores in patients with no shortening of the femoral neck, the study remained inconclusive due to the very low sample size $(\mathrm{n}=13$ for SF-36 data) and subsequently low event rate. In the literature, studies with low event rates have been reported to be at risk for producing exaggerated treatment effects. ${ }^{19}$

The purpose of this study was first, to assess the incidence of shortening of the femoral neck and varus collapse in ambulatory patients after internal fixation of isolated fractures of the neck of the femur with multiple cancellous screws, and secondly, to determine its impact on function using multiple validated functional outcome and radiological measures in a larger cohort of patients. We hypothesised that 1) shortening and varus collapse of the neck are common after hip fracture, and 2) that shortening and varus collapse have an adverse effect on patients' physical function despite successful healing of the fracture. 


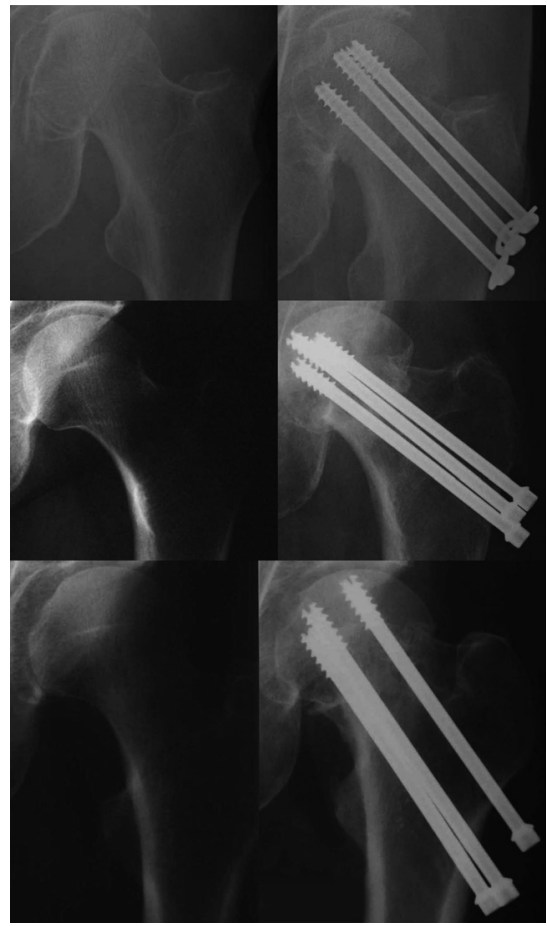

Fig. 1

Radiographs showing typical examples for the three degrees of shortening: the top image demonstrates no/mild shortening $(<5 \mathrm{~mm})$, the middle image moderate shortening $(5 \mathrm{~mm}$ to 10 $\mathrm{mm})$, and the bottom image severe shortening (> $10 \mathrm{~mm}$ ).

\section{Patients and Methods}

We conducted an observational cohort study of patients presenting to four university medical centres in Europe (Aarhus University, Denmark), Canada (McMaster University, Ontario) and the United States (University of Minnesota, Minnesota and University of Mississippi, Mississippi) with a successfully healed intracapsular fracture of the hip after internal fixation with cancellous screws.

Eligibility criteria and identification of eligible patients. Patients eligible for the study included those who were skeletally mature and had an isolated intracapsular fracture of the hip which had united after treatment with multiple cancellous screws. Patients were excluded if 1) other fractures were present, 2) their fracture had not been treated with multiple cancellous screws, 3) the fracture was pathological and associated with a tumour, 4) treatment had resulted in nonunion, 5) osteonecrosis of the femoral head had occurred, 6) there was further surgery of the affected hip for any reason other than for removal of the hardware, 7) they were mentally impaired, 8) they were not able to walk before sustaining the fracture, 9) their radiographs were incomplete, 10) there had been previous surgery to the affected hip, and 11) there had been previous surgery to the opposite hip, as this was needed for comparison. Each of the

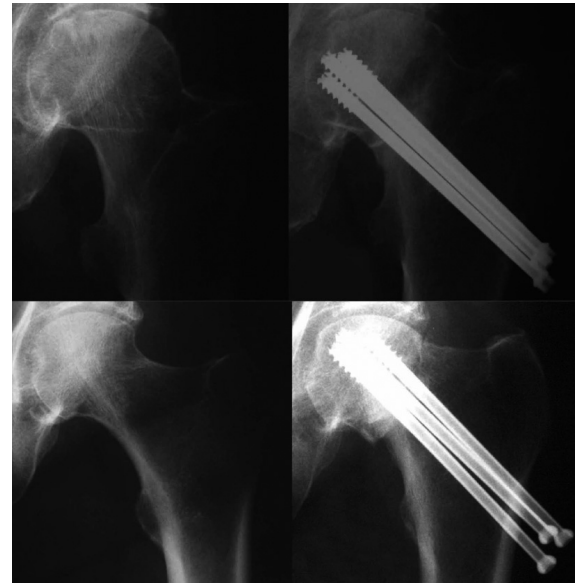

Fig. 2

Radiographs showing typical examples of moderate and severe varus collapse: the top image demonstrates moderate varus collapse $\left(5^{\circ}\right.$ to $10^{\circ}$ ) and moderate shortening ( $5 \mathrm{~mm}$ to $10 \mathrm{~mm}$ ) whereas the bottom image demonstrates severe varus collapse $\left(>10^{\circ}\right)$ and moderate shortening (5 $\mathrm{mm}$ to $10 \mathrm{~mm}$ ).

four centres conducted a search of their database for intracapsular fractures of the hip, and the eligibility criteria were applied to those patients.

Baseline parameter. We recorded the following details for each patient: age, gender, fracture type (displaced/ undisplaced), quality of reduction, number of screws used, the use of washers, the screw configuration (triangle, inverted triangle, vertical, diamond) and duration of follow-up. We measured the alignment of the fracture using Garden's index. ${ }^{20}$ Those reductions which met Garden's criteria $\left(160^{\circ}\right.$ to $180^{\circ}$ in anteroposterior and lateral plane) were deemed acceptable and those that did not were deemed unacceptable. Patients were asked whether they walked with a limp, used a walking aid or had pain before they sustained the intracapsular fracture of the hip.

Outcome measures. The primary outcome measure of this study was the SF-36 physical functioning subscore. ${ }^{21-23}$ Secondary outcome measures of physical function were the SF-36 role physical subscore, the SF-36 physical component summary measure and the EuroQol questionnaire (EQ-5D) index score. ${ }^{21-29}$ Other secondary outcome measures included the remaining SF-36 subscores (bodily pain, general health, vitality, social functioning, role emotional, mental health, mental component summary measure) and self-reported health status on a visual analogue scale which is part of the EQ-5D. Both scores are well validated and widely used. ${ }^{21-28}$ Qualitative assessment of shortening and varus collapse. In each case, all radiographs were independently assessed by three orthopaedic surgeons (OB, JS, MB) who were blinded to the functional outcome. We stratified the degree of shortening and varus collapse into three categories: none/mild (within $\left.5 \mathrm{~mm} / 5^{\circ}\right)$, moderate $\left(5 \mathrm{~mm}\right.$ to $10 \mathrm{~mm} / 5^{\circ}$ to $10^{\circ}$ ) and 


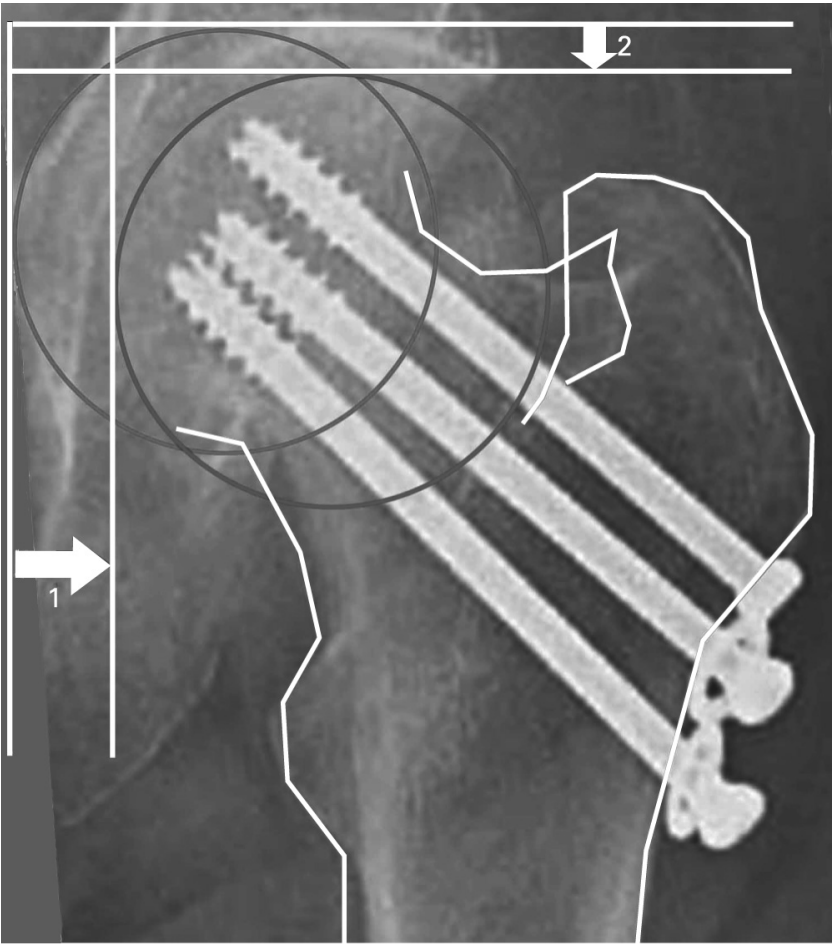

Fig. 3

Radiograph showing femoral neck shortening measurements in the horizontal (abductor moment arm shortening/offset) and vertical planes (femoral length reduction). The contralateral uninjured proximal femur is outlined. Subsequently the outline is overlapped with the injured side and horizontal (indicated by arrow 1) and vertical (indicated by arrow 2) shortening is measured, taking into account the known width of the screws.

severe $\left(>10 \mathrm{~mm} />10^{\circ}\right)$ (Figs 1 and 2$)$. Shortening and varus malalignment were measured on all post-operative radiographs by comparison with the other hip. Disagreements were resolved by consensus. Inter-observer reliability was determined by calculating the intra-class correlation coefficient using SPSS (SPSS Inc., Chicago, Illinois).

Quantitative assessment of femoral neck shortening. Shortening of the femoral neck was also assessed quantitatively in two planes: horizontal, measuring shortening of the abductor moment arm, also known as 'offset' in the context of hip arthroplasty, and vertical indicating reduction in femoral length. The most recent anteroposterior (AP) radiograph of the fractured hip was compared to the uninjured side on AP radiographs taken at the time of the injury. Both radiographs were scanned and graphic software (Macromedia Fireworks, Macromedia Inc., San Francisco, California) was used to compare the two by overlapping and outlining them (Fig. 3).

Radiological assessment of shortening was completed by an independent reviewer (MZ) before the assessment of functional outcome so as to prevent measurement bias. Details of the measurement technique have been previously described in a pilot study, ${ }^{18}$ which showed a substantial intra-observer agreement of measurements of radiographic shortening (intra-class correlation $=0.82 ; 95 \%$ confidence interval (CI) 0.51 to 0.95 ). We also measured the extent of any screw backout.

Assessment of functional outcome. We contacted all patients by telephone and assessed their functional outcome using the SF-36 and the EQ-5D questionnaires. Interviewers were blinded to the results of the radiological analysis.

We also asked each patient nine questions about their preoperative condition and their functional outcome: the presence or absence of a limp, the use of walking aids and the degree of pain before fracture and currently. They were also asked whether they were satisfied with their hip surgery, whether there were any complications, and if they had needed a revision surgery.

Sample size calculation. We based the sample size on our primary outcome, the SF-36 physical functioning subscore. A pilot study of 13 patients generated a 41-point difference in the SF-36 physical functioning subscores between intracapsular fractures of the hip which had healed in a shortened position $(\geq 5 \mathrm{~mm})$ and those with no or minimal shortening $(<5 \mathrm{~mm}) .{ }^{18}$ Studies with low event rates have been reported to be at risk of producing exaggerated treatment effects. ${ }^{19}$ Consequently, we believed that the magnitude of the observed treatment effect was likely to be grossly exaggerated owing to the small sample size, and therefore chose a more conservative difference of 20 points as the basis for our calculation of sample size.

Assuming a reported mean SD of 23 points in the SF-36 physical functioning subscore ${ }^{22}$ and a standard $\alpha$-error of 0.05 (p-value) we calculated that we would need 21 patients in each group, shortened versus not shortened, to be able to detect a difference of 20 points with $80 \%$ power between groups. On the basis of our pilot study we assumed the incidence of shortening to be $30 \%$, which meant that we needed a total of 70 patients in the study to generate the required number with shortening of the femoral neck.

Data analysis. Data were analysed descriptively by using proportions and frequencies for categorical variables, and means, SDs and ranges for continuous variables. We used SPSS software (SPSS Inc.) throughout.

We compared cases with no shortening $(<5 \mathrm{~mm})$ with cases with shortening ( $\geq 5 \mathrm{~mm}$ ) using Student's $t$-test. We also conducted an analysis of variance (ANOVA) with leastsquared differences adjustment for multiple testing to compare continuous outcomes (SF-36 and EQ-5D scores and radiographic shortening) between patients with the three defined degrees of shortening of the femoral neck. We adjusted for multiple comparisons to guard against the increased risk of false-positive results associated with these. We analysed the varus collapse data in the same way. Differences in dichotomous outcomes between groups were analysed using a chi-squared test for trends. All statistical tests were two-tailed.

Lastly, we performed a multivariate linear regression analysis to evaluate the impact and the interaction of the degree of shortening of the femoral neck, the degree of 


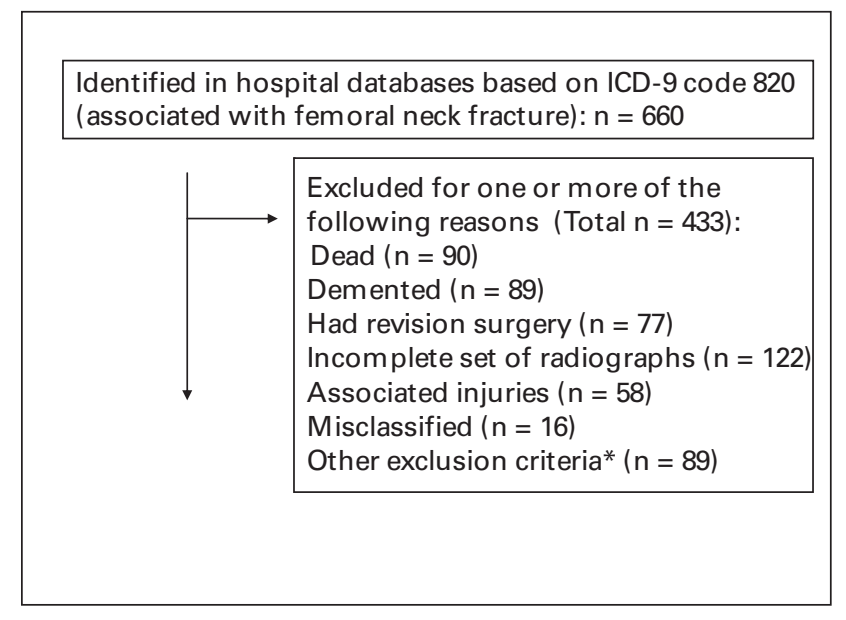

Eligible for inclusion in study and contacted: $n=127$

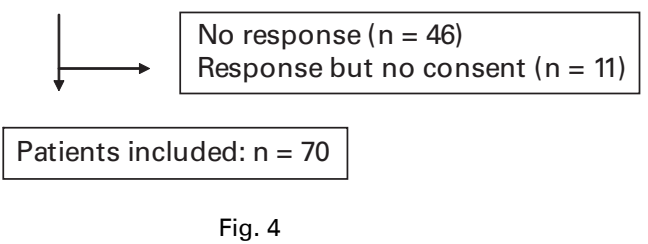

Flowchart showing patient selection and exclusion criteria. *Other exclusion criteria were one or more of the following: osteonecrosis of the femoral head, no contact information on file, patient not skeletally mature, patient non-ambulatory, severe hearing disability, treatment other than cannulated screws, nonunion, pathological fracture and/or contralateral fixation/arthroplasty.

varus collapse, the amount of screw back out, the type of fracture, the age of the patient and the duration of followup on the physical functioning SF-36 subscore. Pearsons's correlation coefficient was calculated to determine the association between shortening of the femoral neck and varus collapse. A p-value of $<0.05$ was considered statistically significant.

\section{Results}

We identified 127 patients suitable for inclusion (Fig. 4). A total of 70 were successfully contacted and consented to take part in the study. The cohort included the 13 patients from the initial pilot study. ${ }^{18}$ The SF-36 and radiological data were collected for each patient and EQ-5D data were obtained from 59 patients. The mean follow-up was for 20 months (5 to 105 ).

Study population/technical aspects of surgery. There were 52 women $(74 \%)$ and 18 men $(26 \%)$ with a mean age of 71 years (20 to 90$)$, of whom $45(64 \%)$ had sustained an undisplaced intracapsular fracture. All but one fracture was fixed with three screws: one was fixed with four. In 41
(59\%) an inverted triangle screw configuration was chosen, in $22(31 \%)$ a triangle with the apex on top and in six $(9 \%)$ a vertical screw configuration. A diamond shape configuration was chosen for one patient. Washers were used in ten patients $(14 \%)$. The quality of reduction was acceptable in all but one case according to Garden's alignment index. ${ }^{20}$

\section{Radiological assessment of shortening and varus collapse of the femoral neck}

Intra-operative shortening and varus malalignment. There was no/mild shortening and no/mild varus malalignment in 64 of 70 cases $(91 \%)$ when comparing the immediate postoperative radiographs to the intact contralateral side. Despite the acceptable quality of reduction by Garden's alignment index in all but one case, when our more critical assessment of shortening and varus malalignment was applied, six cases $(9 \%)$ were found to have been fixed with shortening of $5 \mathrm{~mm}$ or more and/or $5^{\circ}$ or more of varus malalignment.

Shortening and varus malalignment at follow-up. At followup the femoral neck had healed in a shortened position in 46 patients $(66 \%)$ and in 27 of the $70(39 \%)$ some degree of varus collapse had occurred. Overall only 23 of 70 patients $(33 \%)$ demonstrated neither shortening of the femoral neck of $>5 \mathrm{~mm}$ nor varus collapse of $>5^{\circ}$.

Shortening was no/mild $(<5 \mathrm{~mm})$ in 24 cases $(34 \%)$, moderate $(5 \mathrm{~mm}$ to $10 \mathrm{~mm})$ in $25(36 \%)$ and severe $(>10$ $\mathrm{mm}$ ) in $21(30 \%)$ (intra-class correlation coefficient 0.70 : $95 \%$ CI 0.56 to $0.80 ; \mathrm{p}<0.001$ ) (Table I). The mean length of the abductor moment arm decreased by $7 \mathrm{~mm}(0$ to 23$)$ and the mean femoral length by $9 \mathrm{~mm}$ (0 to 34). The mean screw backout was $9 \mathrm{~mm}$ ( 0 to 27). The differences between the three groups (none/mild, moderate, severe shortening) were highly significant for all three measurements, the highest values occurring in the severe shortening group $(\mathrm{p}<0.001)$ (Table II).

Varus collapse was moderate $\left(5^{\circ}\right.$ to $\left.10^{\circ}\right)$ in 7 of 70 cases $(10 \%)$ and severe $\left(>10^{\circ}\right)$ in 20 of 70 cases $(29 \%)$ (Table III). Varus collapse correlated moderately with shortening of the femoral neck (Pearson's correlation coefficient 0.66; $\mathrm{p}<0.001)$. In one case varus collapse occurred without shortening, whereas in 20 of 70 cases $(29 \%)$ shortening occurred without varus collapse (intra-class correlation coefficient $0.77: 95 \%$ CI 0.68 to $0.85 ; \mathrm{p}<0.001$ ).

\section{Functional outcome}

Primary outcome: SF-36 physical functioning score. Shortening of the femoral neck: there were statistically significant differences between patients with no/mild shortening $(<5 \mathrm{~mm})$ and patients with moderate or severe shortening ( $\geq 5 \mathrm{~mm}$; 74 points $v s 48$ points, effect size 1.1, $\mathrm{p}<0.001$ ). We also found statistically significant differences in SF-36 physical functioning scores related to the degree of shortening $(\mathrm{p}<0.001)$. Patients with no/mild shortening scored a mean of 74 points (95\% CI 63 to 84), compared to those with moderate shortening with 53 points (95\% CI 43 to 64) 


Table I. Severity of shortening of the femoral neck based on the type of
fracture
\begin{tabular}{lrr}
\hline Shortening & Displaced fractures (\%) & Undisplaced fractures (\%) \\
\hline No/mild & $8 / 25(32)$ & $16 / 45(35)$ \\
Moderate & $4 / 25(16)$ & $21 / 45(47)$ \\
Severe & $13 / 25(52)$ & $8 / 45(18)$ \\
\hline
\end{tabular}

Table II. Radiographic measures in relation to degree of shortening of the femoral neck

\begin{tabular}{lllll}
\hline & Total & No/mild shortening & Moderate shortening & Severe shortening \\
\hline Mean decrease in abductor moment arm in $\mathrm{mm}$ & 7 & 3 & 9 & 10 \\
Mean decrease in length of femur in mm & 9 & 3 & 8 & 18 \\
Mean distance of screws backing out in $\mathrm{mm}$ & 8 & 3 & 6 & 14 \\
\hline
\end{tabular}

Table III. Severity of varus collapse based on the type of fracture

\begin{tabular}{lrr}
\hline Varus collapse & Displaced (\%) & Undisplaced (\%) \\
\hline No/mild & $12 / 25(48)$ & $31 / 45(69)$ \\
Moderate & $2 / 25(8)$ & $5 / 45(11)$ \\
Severe & $11 / 25(44)$ & $9 / 45(20)$ \\
\hline
\end{tabular}

and patients with severe shortening with 42 points $(95 \%$ CI 29 to 54) (Fig. 5).

Varus collapse point estimates suggested that varus collapse has a negative effect on the SF-36 physical functioning score, but the differences were not statistically significant either when comparing patients with $<5^{\circ}$ and $\geq 5^{\circ}(60$ vs 52 points, $\mathrm{p}=0.33$ ), or between the three groups with $<5^{\circ}$, $5^{\circ}$ to $10^{\circ}$ and $>10^{\circ}$ of varus collapse $(\mathrm{p}=0.29)$. Patients with no/mild varus collapse scored a mean 60 points $(95 \%$ CI 51 to 69) compared to those with moderate varus collapse with 56 points (95\% CI 35 to 78 ) and patients with severe varus collapse with 51 points (95\% CI 37 to 64 ).

Secondary outcomes. Differences in the EQ-5D index score were also statistically significant between patients with no/ mild, moderate and severe shortening of the femoral neck (0.83 vs 0.81 vs 0.68 points, $\mathrm{p}=0.05$ for overall ANOVA three-group comparison, $\mathrm{p}=0.02$ for no/mild $v s$ severe and $\mathrm{p}=0.05$ for moderate $v$ s severe shortening).

When comparing patients with no/mild $(<5 \mathrm{~mm})$ femoral neck shortening to those with moderate or severe shortening ( $\geq 5 \mathrm{~mm}$ ), there were significantly lower scores for patients with shortened fractures $\geq 5 \mathrm{~mm}$ in the SF- 36 physical component summary scale ( 40 vs 46 points; $\mathrm{p}=0.02$ ) and SF-36 vitality scale (52 vs 64 points; $\mathrm{p}=0.035$ ), which indicated increasing impairment of function with a greater degree of shortening. There were also statistically insignificant trends towards lower scores for patients with moderate or severe shortening for the following SF-36 domains: role physical (69 vs 84 points; $\mathrm{p}=0.13$ ), role emotional (79 vs 92 points; $\mathrm{p}=0.16)$, and bodily pain (54 vs 60 points; $\mathrm{p}=0.45$ ) (Table IV).

There were no statistically significant differences for any SF-36 sub- or summary scores or EQ-5D outcome measures between patients with no/mild, moderate and severe varus collapse.

Functional outcome and pain compared to before fracture. A comparison of the proportions of patients walking with a limp and using walking aids before they sustained a fracture of the femoral neck showed no differences between the subgroups with no/mild, moderate and severe shortening $(\mathrm{p}=0.83)$ as well as varus collapse $(\mathrm{p}=0.44)$, indicating a similar baseline functional status (Tables V and VI). When comparing the degree of shortening at the final follow-up, the differences in the proportions of patients who walked with a limp and those using a walking aid were highly significant statistically; a greater degree of shortening resulted in more patients who walked with a limp and used a walking aid (both $\mathrm{p}<0.01$ ) (Table V). Similarly, more patients with varus collapse, needed to use a walking aid $(\mathrm{p}<0.01)$ (Table VI).

Factors affecting functional outcome. Multivariate linear regression analysis with the SF-36 physical functioning score as the dependent variable showed that the degree of shortening of the femoral neck was the only statistically significant variable $(\mathrm{p}<0.001)$. The degree of varus collapse showed a tendency to be associated with the SF-36 physical functioning subscore, but did not reach statistical significance $(\mathrm{p}=0.09)$. Shortening and varus collapse accounted for $22 \%$ of the variability in failure of fixation $\left(\mathrm{R}^{2}=0.22\right)$. The following variables were not predictive of the SF-36 physical functioning subscore: age $(\mathrm{p}=0.28)$, gender $(\mathrm{p}=0.69)$, type of fracture $(\mathrm{p}=0.36)$, duration of follow-up $(\mathrm{p}=0.69)$ and degree of screw backout $(\mathrm{p}=0.59)$.

Satisfaction with surgery and complications. Overall, 12 of 70 patients $(18 \%)$ were extremely satisfied with their surgery, $31(44 \%)$ were very satisfied, $20(28 \%)$ moderately 


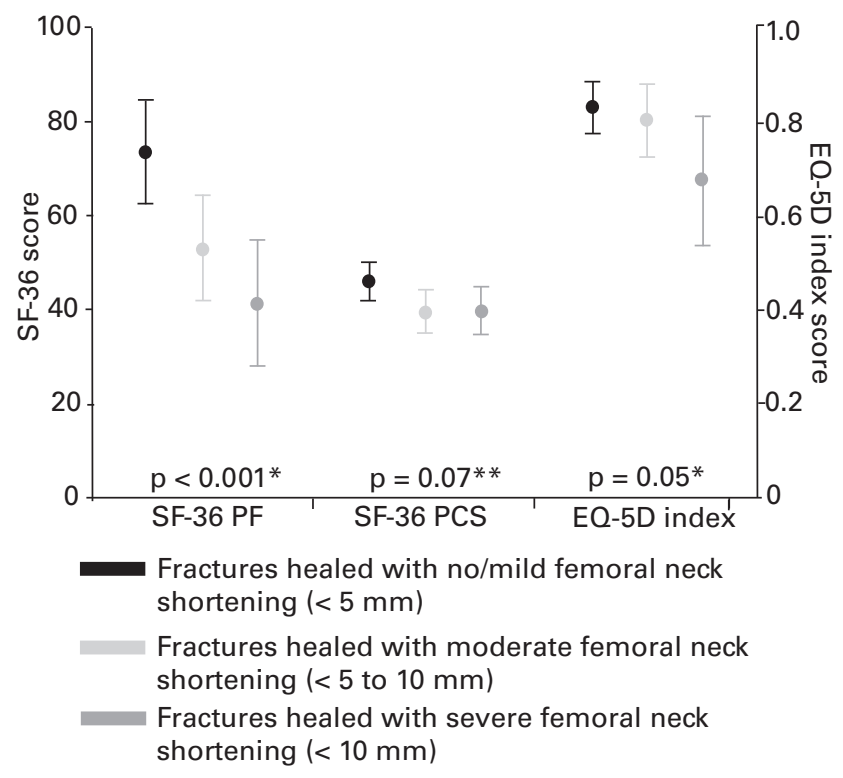

Fig. 5

Graph showing the point estimates (dots) and associated 95\% confidence intervals (bars) for the three main scores that relate to physical function (SF-36 physical functioning (PF), SF-36 physical component summary score (PCS) and the EQ-5D index summary score) between the three different shortening subgroups: no/mild $(<5 \mathrm{~mm})$, moderate $(5 \mathrm{~mm}$ to $10 \mathrm{~mm})$, and severe $(\geq 10 \mathrm{~mm})$. * Note the strong statistical significance for the SF-36 PF scores, which is also present for each subgroup comparison. Differences in EQ-5D index scores are also statistically significant $(p<0.05$ ) except for the comparison of no/mild to moderate shortening. ** There is no overall statistical significance for the SF-36 PCS score; however, single group comparisons for no/mild shortening with the other groups are significant (no/mild vs moderate: $\mathrm{p}=0.05$ and no/mild $v s$ severe: $\mathrm{p}=0.02$ ).

satisfied, one (1\%) a little satisfied and six (9\%) were not at all satisfied. One patient developed a trochanteric bursitis. No patient underwent any revision procedure, except for one who needed their metalwork removed.

\section{Discussion}

Despite its importance in the literature of total hip replacement, the adverse effects of shortening of the femoral neck have largely been overlooked by orthopaedic trauma surgeons. This study has shown that shortening of $>5 \mathrm{~mm}$ occurs in two-thirds of intracapsular fractures of the hip fixed with multiple cancellous screws and shortening has a significant impact on physical function. The incidence of limping and the need for a walking aid significantly increased as the femoral neck shortened. Similarly, the mean SF-36 physical functioning scores decreased significantly from 74 to 53 to 42 points, suggesting a gradient effect. The observed differences in SF-36 physical functioning scores and the SF-36 physical component summary measure represent more than one SD and are widely regarded as clinically important (SD for SF-36 physical functioning = 23 points; SD for SF-36 physical component summary $=10$ points) ${ }^{30,31}$ Using Cohen's concept ${ }^{30}$ of effect sizes, the differences in the SF-36 physical functioning scores between the no mild and moderate, and the no/mild and severe shortening cohorts can be expressed as an effect size of 0.40 and 0.75 , respectively. Cohen defined effect sizes as small (0.2), medium (0.5) and large (0.8). ${ }^{30}$

Because function was assessed by two validated and reliable functional outcome instruments and shortening was evaluated by several surgeons supported by an independent quantitative assessment, it seems likely that the observed effect of decreasing function with increasing femoral neck shortening is real. The patients' baseline pre-injury assessment indicated that all the subgroups were functionally similar: selection bias, therefore, appears to have been limited. Furthermore, the similarity in SF-36 general health subscores, as well as the EQ-5D selfrated general health scores between patients with different degrees of shortening make it unlikely that functional outcome scores were strongly influenced by comorbidities.

We are unsure whether the changes in the abductor moment arm due to shortening of the femoral neck are wholly responsible for the differences in physical function that we have seen, but it appears to be part of the reason for the observed decline in function with increasing shortening. Another possible explanation for the decline in physical function might be local irritation due to backing out of the screws, although this was not a significant predictor $(\mathrm{p}=0.59)$ of the SF-36 physical functioning score when evaluated in a multivariate regression model. A further possibility is that malalignment between the femoral head and the acetabulum may impair function if a nonanatomical reduction of the fracture is achieved. Although, grossly, the hip joint is a congruent ball and socket joint, it has been pointed out by Garden ${ }^{20}$ that this congruency is not exact, and failure to restore the appropriate relationship between the head and the acetabulum might have a negative effect on outcome. The amount of shortening of the neck observed in our study confirms that of previous investigations. In a roentgenstereophotogrammetric analysis (RSA) of 16 femoral neck fractures treated with two cannulated screws, Ragnarsson et $\mathrm{al}^{32}$ found a mean shortening of the neck of $13 \mathrm{~mm}$ in nine healed fractures which had initially been displaced. Necrosis of the head developed in three of these. Overall, they found that fractures healed if they became stable within six months, but those with continued micromovement and shortening for nine to 12 months were prone to develop osteonecrosis; no fracture with continued micromovement beyond 12 months healed. Molnar and Routt ${ }^{33}$ recently suggested that fractures of the femoral neck should be anatomically reduced through a modified Smith-Petersen approach, and fixed with a plate directly applied across the fracture site at the neck. This would prevent femoral neck shortening and is, in our opinion, a concept worth considering. We believe that a potential solution to prevent the functional impairment that occurs with shortening might be to use a lateral side plate that allows the insertion of multiple non-parallel lag screws into the head. These could be then locked into the plate, which would be fixed to the shaft with a few screws. The fracture could be compressed during screw insertion, 
Table IV. EuroQol (EQ-5D) domains in relation to shortening of the femoral neck $(n=59)$

\begin{tabular}{|c|c|c|c|}
\hline & No/mild shortening & Moderate shortening & Severe shortening \\
\hline \multicolumn{4}{|l|}{ Mobility } \\
\hline No problems walking & $11 / 20$ & $10 / 20$ & $5 / 19$ \\
\hline Confined to bed & - & - & $2 / 19$ \\
\hline \multicolumn{4}{|l|}{ Self-care } \\
\hline Some problems washing or dressing & $3 / 20$ & $3 / 20$ & $6 / 19$ \\
\hline Unable to wash or dress & - & - & $1 / 19$ \\
\hline \multicolumn{4}{|l|}{ Usual activities } \\
\hline No problems with performing & $14 / 20$ & $12 / 20$ & $8 / 19$ \\
\hline \multicolumn{4}{|l|}{ Pain/discomfort } \\
\hline No pain or discomfort & $7 / 20$ & $7 / 20$ & $6 / 19$ \\
\hline Moderate pain or discomfort & $13 / 20$ & $12 / 20$ & $10 / 19$ \\
\hline Extreme pain or discomfort & - & $1 / 20$ & $3 / 19$ \\
\hline \multicolumn{4}{|l|}{ Anxiety/depression } \\
\hline Not anxious or depressed & $13 / 20$ & $13 / 20$ & $14 / 19$ \\
\hline Moderately anxious or depressed & $7 / 20$ & $7 / 20$ & $3 / 19$ \\
\hline Extremely anxious or depressed & - & - & $2 / 19$ \\
\hline Index score ${ }^{*}$ & $0.83(0.77$ to 0.89$)$ & $0.81(0.73$ to 0.88$)$ & $0.68(0.54$ to 0.82$)$ \\
\hline
\end{tabular}

Table V. Function and pain at final follow-up versus pre-injury in relation to severity of femoral neck shortening ( $\mathrm{n}=59$ )

\begin{tabular}{|c|c|c|c|c|c|c|c|c|c|}
\hline & \multicolumn{3}{|c|}{ No/mild shortening } & \multicolumn{3}{|c|}{ Moderate shortening } & \multicolumn{3}{|c|}{ Severe shortening } \\
\hline & \multirow{2}{*}{$\begin{array}{l}\begin{array}{l}\text { Before fracture } \\
(\%)\end{array} \\
3 / 20(15)\end{array}$} & \multicolumn{2}{|c|}{$\begin{array}{l}\text { After fracture fixation } \\
(\%)\end{array}$} & \multirow{2}{*}{$\begin{array}{l}\text { Before fracture } \\
(\%)\end{array}$} & \multicolumn{2}{|c|}{$\begin{array}{l}\text { After fracture fixation } \\
(\%)\end{array}$} & \multirow{2}{*}{$\begin{array}{l}\text { Before fracture } \\
(\%)\end{array}$} & \multicolumn{2}{|c|}{$\begin{array}{l}\text { After fracture fixation } \\
(\%)\end{array}$} \\
\hline Walk with a limp & & $6 / 20(30)$ & & & $12 / 21$ & & & $14 / 18(78)$ & \\
\hline Use walking aids & $0 / 20(0)$ & $3 / 20(15)$ & & $1 / 21$ & $9 / 21 \quad(43)$ & & $0 / 18(0)$ & $15 / 18(83)$ & \\
\hline \multirow[t]{5}{*}{ Bothered by pain } & $1 / 20(5)$ & Not at all: & $7 / 20(35)$ & $2 / 21 \quad(10)$ & Not at all: & $7 / 21 \quad(33)$ & $0 / 18(0)$ & Not at all: & $4 / 18 \quad(22)$ \\
\hline & & A little: & $9 / 20(45)$ & & A little: & $4 / 21 \quad(19)$ & & A little: & $7 / 18$ (39) \\
\hline & & Moderately: & $: 3 / 20 \quad(15)$ & & Moderately: & $6 / 21 \quad(29)$ & & Moderately: & $6 / 18$ (33) \\
\hline & & Very: & $0 / 20(0)$ & & Very: & $2 / 21 \quad(10)$ & & Very: & $3 / 18(17)$ \\
\hline & & Extremely: & $1 / 20(5)$ & & Extremely: & $2 / 21 \quad(10)$ & & Extremely: & $0 / 18(0)$ \\
\hline
\end{tabular}

Table VI. Function and pain at final follow-up versus pre-injury in relation to the severity of varus collapse $(n=59)$

\begin{tabular}{|c|c|c|c|c|c|c|c|c|c|}
\hline & \multicolumn{3}{|c|}{ No/mild varus collapse } & \multicolumn{3}{|c|}{ Moderate varus collapse } & \multicolumn{3}{|c|}{ Severe varus collapse } \\
\hline & $\begin{array}{l}\text { Before fracture } \\
(\%)\end{array}$ & \multicolumn{2}{|c|}{$\begin{array}{l}\text { After fracture fixation } \\
(\%)\end{array}$} & $\begin{array}{l}\text { Before fracture } \\
(\%)\end{array}$ & \multicolumn{2}{|c|}{$\begin{array}{l}\text { After fracture fixation } \\
(\%)\end{array}$} & $\begin{array}{l}\text { Before fracture } \\
(\%)\end{array}$ & \multicolumn{2}{|c|}{$\begin{array}{l}\text { After fracture fixation } \\
(\%)\end{array}$} \\
\hline Walk with a limp & $4 / 38(11)$ & 15/38 (39) & & $1 / 4(25)$ & $3 / 4(75)$ & & $3 / 17 \quad(18)$ & $11 / 17 \quad(65)$ & \\
\hline $\begin{array}{l}\text { Use assistance walking } \\
\text { devices }\end{array}$ & $1 / 38 \quad(3)$ & $14 / 38$ (37) & & $0 / 4(0)$ & $3 / 4 \quad(75)$ & & $0 / 17(0)$ & $12 / 17(71)$ & \\
\hline \multirow[t]{5}{*}{ Bothered by pain } & $2 / 38 \quad(5)$ & Not at all: & $12 / 38$ (32) & $1 / 4(25)$ & Not at all: & $2 / 4(50)$ & $0 / 17(0)$ & Not at all: & $4 / 17 \quad(24)$ \\
\hline & & A little: & $12 / 38$ (32) & & A little: & $1 / 4(25)$ & & A little: & $7 / 17(41)$ \\
\hline & & Moderately: & $10 / 38(26)$ & & Moderately & $: 1 / 4(25)$ & & Moderately & : 4/17 (24) \\
\hline & & Very: & $2 / 38 \quad(5)$ & & Very: & $0 / 4(0)$ & & Very: & $3 / 17(18)$ \\
\hline & & Extremely: & $2 / 38 \quad(5)$ & & Extremely: & $0 / 4(0)$ & & Extremely: & $1 / 17(6)$ \\
\hline
\end{tabular}

thereby stimulating healing, but preventing neck shortening and possibly also varus collapse due to the non-parallel and locked nature of the screws.
Varus collapse was less common in our study than shortening $(39 \%$ vs $66 \%)$ and had a similar, but smaller and statistically non-significant effect on physical functioning. Although there 
was clearly a high correlation suggesting an interaction between the two (correlation coefficient 0.66), regression analysis showed shortening to be the single largest predictor of the SF-36 physical functioning score.

The present study has several strengths. We used two reliable and highly validated outcome instruments (SF-36 and EQ-5D) to assess functional outcome. ${ }^{21-29}$ Our eligibility criteria were comprehensive and excluded all but isolated fractures in patients able to walk. Although this limited the number available, our sample size was sufficiently large to detect clinically relevant differences in the primary outcome measure. Femoral neck shortening and varus collapse were assessed by several surgeons and resulted in a high degree of inter-observer reliability. Shortening was also measured quantitatively using a method that has demonstrated a high intra-observer reliability.

However, despite high intra-observer agreement, the measurements of shortening may be affected by differences in rotation between the control and follow-up radiographs. The quantitative radiographic measurements should therefore only be regarded as adjunct data points to the surgeons' assessment of shortening. Further limitations of this study relate to its retrospective nature and include possible selection bias and limited follow-up.

Our findings have substantial clinical relevance. Whereas fracture healing after multiple screw fixation of intracapsular fractures of the hip has been thought to constitute successful treatment, our findings imply that these criteria are insufficiently stringent. Fractures that heal in a shortened position do not necessarily result in satisfactory function. The concept of 'sliding' afforded by multiple parallel screws is possibly weighted too heavily on the side of the biology of the fracture at the expense of its mechanics.

We found that a large proportion of intracapsular fractures of the hip fixed with cancellous screws heal in a shortened position $(66 \%)$, with collapse into varus $(39 \%)$. This has a negative effect on function. Shortening of the femoral neck was the single largest factor adversely affecting the SF-36 physical functioning score. Healing of an intracapsular fracture after internal fixation with multiple parallel screws should not be regarded as a success without assessment of the patient's functional outcome.

\section{Supplementary material}

$\ddot{e}$

A further figure showing the SF-36 scores in shortened and non-shortened fractures of the femoral neck is available with the electronic version of this article on our website at www.jbjs.org.uk

This study was funded by a grant from 'AO North America'. M. Zlowodzki was funded in part by a clinical research fellowship grant from the 'Osteosynthesis and Trauma Care Foundation'.

No benefits in any form have been received or will be received from a commercial party related directly or indirectly to the subject of this article.

\section{References}

1. Cooper C, Campion G, Melton LJ 3rd. Hip fractures in the elderly: a world-wide projection. Osteoporos Int 1992;2:285-9.
2. Cummings SR, Rubin SM, Black D. The future of hip fractures in the United States: numbers, costs, and potential effects of postmenopausal estrogen. Clin Orthop 1990;252:163-6.

3. Gullberg B, Johnell 0, Kanis JA. World-wide projections for hip fracture. Osteoporos Int 1997;7:407-13.

4. Parker MJ. The management of intracapsular fractures of the proximal femur. J Bone Joint Surg [Br] 2000;82-B:937-41.

5. Parker MJ, Stockton G. Internal fixation implants for intracapsular proximal femoral fractures in adults. Cochrane Database Syst Rev 2001:CD001467.

6. Parker MJ, Blundell C. Choice of implant for internal fixation of femoral neck fractures: meta-analysis of 25 randomised trials including 4,925 patients. Acta Orthop Scand 1998;69:138-43

7. Tencer AF. Biomechanics of fractures and fixation. In: Bucholz RW, Heckman JD, eds. Rockwood and Green's fractures in adults. Vol. 1. Philadelphia: Lippincott Williams \& Wilkins, 2001:3-35.

8. Swiontkowski MF. Intracapsular hip fractures. In: Browner BD, Jupiter JB, Levine AM Trafton PF, eds. Skeletal trauma: fractures, dislocations, ligamentous injuries. Vol. 2 Philadelphia: WB Saunders, 1998:1751-832.

9. Parker MJ, Porter KM, Eastwood DM, Schembi Wismayer M, Bernard AA Intracapsular fractures of the neck of femur: parallel or crossed garden screws? J Bone Joint Surg [Br] 1991;73-B:826-7.

10. Parker MJ. Parallel garden screws for intracapsular femoral fractures. Injury 1994:25:383-5.

11. Swiontkowski MF, Winquist RA, Hansen ST Jr. Fractures of the femoral neck in patients between the ages of twelve and forty-nine years. J Bone Joint Surg [Am] 1984;66-A:837-46.

12. Bray TJ. Femoral neck fracture fixation: clinical decision making. Clin Orthop 1997;339:20-31.

13. Charles MN, Bourne RB, Davey JR, et al. Soft-tissue balancing of the hip: the role of femoral offset restoration. Instr Course Lect 2005;54:131-41.

14. Davey JR, O'Connor DO, Burke DW, Harris WH. Femoral component offset: its effect on strain in bone-cement. J Arthroplasty 1993;8:23-6.

15. McGrory BJ, Morrey BF, Cahalan TD, An KN, Cabanela ME. Effect of femoral offset on range of motion and abductor muscle strength after total hip arthroplasty. J Bone Joint Surg [Br] 1995;77-B:865-9.

16. Sakalkale DP, Sharkey PF, Eng K, Hozack WJ, Rothman RH. Effect of femoral component offset on polyethylene wear in total hip arthroplasty. Clin Orthop 2001;388:125-34

17. Zlowodzki M, Jönsson A, Paulke R, Kregor PJ, Bhandari M. Shortening after femoral neck fracture fixation: is there a solution? Clin Orthop 2007:461:213-18.

18. Zlowodzki M, Ayeni O, Petrisor BA, Bhandari M. Femoral shortening after fracture fixation with multiple cancellous screws: incidence and effect on function. J Trauma 2008;64:163-9

19. Montori VM, Devereaux PJ, Adhikari NK, et al. Randomized trials stopped early for benefit: a systematic review. JAMA 2005;294:2203-9.

20. Garden RS. Malreduction and avascular necrosis in subcapital fractures of the femur J Bone Joint Surg [Br] 1971;53-B:183-97.

21. Stewart A, Ware JE. Measuring functioning and well-being: the medical outcomes study approach. Durham: Duke University Press, 1992.

22. Ware JE, Snow KK, Kosinski M, Gandek B. Health Survey: manual and Interpretation Guide. Boston, Lincoln: The Health Assessment Lab \& Quality Metric Inc., 1996.

23. Ware JE Jr, Sherbourne CD. The MOS 36-item short-form health survey (SF-36). I: conceptual framework and item selection. Med Care 1992;30:473-83.

24. Fryback DG. A US valuation of the EQ-5D. Med Care 2005;43:199-200.

25. Johnson JA, Coons SJ, Ergo A, Szava-Kovats G. Valuation of EuroOoL (EQ-5D) health states in an adult US sample. Pharmocoeconomics 1998;13:421-33.

26. Shaw JW, Johnson JA, Coons SJ. US valuation of the EQ-5D health states: development and testing of the DI valuation model. Med Care 2005;43:203-20.

27. Badia X, Roset M, Herdman M, Kind P. A comparison of United Kingdom and Spanish general population time trade-off values for EQ-5D health states. Med Decis Making 2001;21:7-16.

28. Dolan P. Modeling valuations for EuroOol health states. Med Care 1997;35:1095-108

29. No authors listed. EuroOol: a new facility for the measurement of health-related quality of life: the Euro0ol Group. Health Policy 1990;16:199-208.

30. Cohen J. A power primer. Psychological Bulletin 1992;112:155-9.

31. Norman GR, Sloan JA, Wyrwich KW. Interpretation of changes in health-related quality of life: the remarkable universality of half a standard deviation. Med Care 2003;41:582-92.

32. Ragnarsson JI, Boquist L, Ekelund L, Karrholm J. Instability and femoral head vitality in fractures of the femoral neck. Clin Orthop 1993;287:30-40.

33. Molnar RB, Routt ML Jr. Open reduction of intracapsular hip fractures using a modified Smith-Peterson surgical exposure. J Orthop Trauma 2007;21:490-4. 